\title{
Introduction: special issue of air quality, atmosphere and health for air pollution and health: bridging the gap from sources-to-health outcomes
}

\author{
Paul A. Solomon
}

Published online: 9 November 2011

(C) Springer Science+Business Media B.V. (outside the USA) 2011

\section{The conference}

The U.S. Environmental Protection Agency has established the National Ambient Air Quality Standards for six principal air pollutants (criteria pollutants): carbon monoxide $(\mathrm{CO})$, lead $(\mathrm{Pb})$, nitrogen dioxide, particulate matter in two size ranges [less than $2.5 \mu \mathrm{m}$ (PM2.5) and less than $10 \mu \mathrm{m}$ (PM10)], ozone, and sulfur dioxide (http://www.epa. gov/air/criteria.html). While associations have been identified between these pollutants and adverse health effects, considerable uncertainty remains with regards to methods and approaches to understanding which gas or particulate components are most toxic, which sources and source combinations emit these compounds and their precursors, the mechanisms of actions of the pollutants and their causal relationships to adverse health effects, effect of confounding factors that obscure the relationship between toxicity and health, and which populations are susceptible. The pollutant - health relationship is all the more complicated for particulate matter since it is composed of many components and is distributed over a wide range of sizes that differentially deposit in human airways (EPA 2006a [ozone criteria document (CD)], EPA 2006b (Pb CD), EPA 2008a [NOx integrated science assessment (ISA)], EPA 2008b (SOx ISA), EPA 2009 (PM ISA), EPA 2010 (CO ISA)). Air pollution and health research continues to reduce these uncertainties across the source-to-health effects paradigm as described by the National Research Council (NRC 1998, 1999, 2001, 2004), EPA (EPA 2006a, b,

P. A. Solomon $(\square)$

Office of Research and Development,

U.S. Environmental Protection Agency,

Las Vegas, NV 89119, USA

e-mail: solomon.paul@epa.gov 2008a, b, 2009, 2010), and Solomon et al. (2011a and references within).

Linking air pollution to adverse health effects and minimizing the risk from air pollution is complicated and requires expertise across a range of scientific disciplines from atmospheric to exposure to health sciences as well as inclusion of air quality managers and policy makers who develop and implement Policies related to reducing air pollution on national, regional, and local scales to protect public health and welfare. Interaction among these groups at different points in time helps to identify gaps in knowledge and suggests future research directions. March 2010 provided one such opportunity through "Air Pollution and Health: Bridging the Gap from Sources to Health Outcomes," an international specialty conference by the American Association for Aerosol Research (AAAR, http:// aaar.2010specialty.org/; Solomon et al. 2011a). The conference was chaired by Drs. Paul A. Solomon (U.S. EPA) and Maria Costantini (HEI) and was designed to help disseminate and integrate results from scientific studies that cut across the range of air pollution and health-related disciplines of the source-to-health effects continuum. Conference objectives are listed in Table 1. The conference addressed the science of air pollution and health within a multipollutant framework, focusing across five key science areas: sources, atmospheric sciences, exposure, dose, and health effects as identified by the NRC (1998). Eight key policy-relevant science questions that integrated across various parts of these science areas formed the basis of the meeting. A ninth question addressed the policy implications of the findings. The science questions are listed in Table 2. This was AAAR's third international specialty conference and extends the findings presented at AAAR's first specialty conference "Particulate Matter: Atmospheric Sciences, Exposure, and the Fourth 
Table 1 Conference objectives

1. Bring together researchers from across the source-to-health outcomes paradigm (NRC 1998) to engage in discussion and rigorous debate regarding the latest information on linking adverse health effects of air pollution to emissions sources and atmospheric pollutants.

2. Communicate effectively the latest information to scientists, air quality mangers in the public and private sectors, and policy makers in support of developing efficient and cost effective approaches to decreasing acute and chronic adverse health effects from air pollution on community and regional scales. The conference theme is multipollutant focusing on the sources, fate, and health effects of ambient air pollutants. The meeting is designed to appeal to a large interdisciplinary international audience.

3. Highlight findings from major measurement, data analysis, and modeling studies and programs conducted since the last AAAR PM and health conference in 2003. Papers and presentations that show linkages from sources to air quality and/or air quality to health outcomes are strongly encouraged.

4. Add significantly to the peer-reviewed literature by publishing research results presented at the conference in a variety of special issues of selected journals and or synthesis papers.

Colloquium on PM and Human Health," Pittsburgh, PA, 2003 (Davisdon et al. 2005).

Results from the 2010 AAAR Air Pollution and Health conference are being published in six special journal issues [Air Quality, Atmosphere and Health-this issue and a second addressing the science questions directly (Solomon 2011a), Inhalation Toxicology (Solomon 2010), Environmental Health Perspectives (Solomon 2011b), Aerosol Science and Technology (Solomon 2011c), and Atmospheric Environment (Solomon et al. 2011b)]. All six special issues will be published by spring 2012 .

\section{This issue}

This special issue of Air Quality, Atmosphere and Health includes selected papers from the Air Pollution and Health Conference that align with the goals and objectives of this journal. Study objectives described in each paper align with the conference science questions as indicated in Table 3.
Key findings also are presented in Table 3 with brief descriptions of the projects given below.

The first paper in this issue presents an overview of the results presented at 2010 Air Pollution and Health Conference described above (Solomon et al. 2011a, this issue). The summary is presented along the lines of the eight science questions and the ninth presenting policy insights based on those findings. Experts in their field related to the topics of each question were asked to integrate and synthesize the results from the presentations and add context and background with peer-reviewed literature. Many of the presentations are noted by abstract number with the abstracts included as electronic supplemental material to the overview paper. Many of the latest and yet to be published findings are described in the overview to ensure the information presented at the conference was captured and to help disseminate the information beyond those that attended the conference. Concluding remarks at the end of the response to each question include a statement about recent advances as well

Table 2 Science questions

1. Pollutants and sources associated with health effects: How does our understanding of the health effects of air pollutants (singly or in mixtures) help identify pollutants that can be linked to sources the control of which would provide maximal health benefits? (overarching theme)

2. Reliability of methods, models, and approaches: How reliable are methods (measurements and models) and approaches (epidemiological and toxicological) for studying and quantifying the links between air pollutants (species and or sources) and adverse health effects?

3. Pollutant characterization and population exposure: How do relevant pollutant properties vary in space and time from sources and in ambient air; what are the implications of these variations for population exposure?

4. Relation between exposure and dose: What advances have been made in understanding the relationships between exposure, both spatially and temporally, and estimates of dose that tie to health outcomes?

5. Mechanisms of action and biomarkers of exposure and effects: Are patterns emerging that relate component(s) of air pollution and/or source types to mechanisms? What is the status of identifying and measuring biomarkers of exposure and/or adverse health effects from air pollution?

6. Susceptible populations: Who are the susceptible populations, what drives different susceptibilities to the same or different air pollutants, and are there susceptibility traits associated with specific health outcomes that are common among the subpopulations?

7. Confounding or other factors: What roles do confounding or other factors have in increasing, decreasing, or obscuring attribution of the true health effects from ambient air pollutants?

8. Accountability: Do actions taken to improve air quality result in reduced ambient concentrations of relevant pollutants, exposure, and health effects, and have we encountered unintended consequences?

9. Regulatory and policy implications: What are the policy implications of our improved understanding of the source to health effect paradigm? 
Table 3 Relationship of special issue paper objectives, as given in Table 2, to conference science questions (SQ)

\begin{tabular}{lll}
\hline $\begin{array}{l}\text { Authors/ } \\
\text { category }\end{array}$ & Study objective & Key finding \\
\hline
\end{tabular}

Emissions characterization

Solomon et To provide an overview of the 2010 Air Pollution and

al. (2011a) Health Conference by engaging experts in the field related to each of the science questions, which formed the basis of the meeting, to respond to the questions based on the material presented at the meeting supplemented with over 200 peer-reviewed papers. In addressing each question, authors also provide Con cluding Remarks noting recent advances and knowledge gaps/research needs. The conclusion consists of policyrelevant insights gleaned from the scientific finding and developed by experts in science and policy.

Miranda et al. To examine PM2.5 mass and composition to better 2011, this understand seasonal variations in concentrations of the issue measured components, the influence of meteorology, physicochemical profiles, and to estimate the number of excess deaths due to PM2.5 concentrations above the WHO PM2.5 standard of $10 \mu \mathrm{g} / \mathrm{m}^{3}$ in six major Brazilian cities, the largest of which was São Paulo, all of which are state capitals in Brazil. It lasted more than a year with daily sampling.

Andrade et al. 2011, this issue

Zielinska et al. 2011, this issue
To identify the sources contributing to PM2.5 mass concentrations in six major cities in Brazil, all being state capitals, including: São Paulo (the largest city in Brazil and one of the largest in the world); Rio de Janeiro; Belo Horizonte; Curitiba; Recife; and Porto Alegre. The specific focus was to quantify the fraction of PM2.5 mass due to motor vehicle emissions, since motor vehicles, burning ethanol, gasohol, and diesel are the primary source of pollution in these cities.

To examine the relationships between vehicle tailpipe and evaporative emissions and resulting pollutant concentration levels observed in an attached garage and
Many key finding are noted and reaffirmed as expected All given the depth and breadth of the conference, which covered most aspects of air pollution from sources to health effects. Of particular note at the conference was the need to have a greater focus on multipollutant science and management approaches that include more direct studies of the mixture of pollutants from sources as well as an emphasis on health studies at ambient concentrations. A number of associations were noted between pollutants and a range of health effects, including mortality. Some of the pollutants included elemental carbon, certain organic species, ultrafine particles, and certain trace elements such as $\mathrm{Ni}, \mathrm{V}$, and $\mathrm{Fe}(\mathrm{II})$, as well as some gaseous pollutants, such as ozone. Ultrafine particles were noted as having strong associations with various cardiovascular and respiratory effects. PMc was associated with respiratory effects, such as asthma. One mechanism repeated and reaffirmed at the meeting included the role of species that generate reactive oxygen species known to increase oxidative stress, and thus, inflammation, which has been linked to numerous adverse health effects.

PM2.5 mass among the cities ranged from $7.3 \mu \mathrm{g} / \mathrm{m}^{3}$ in Recife the city with the lowest population to $28.1 \mu \mathrm{g} / \mathrm{m}^{3}$ in São Paulo with a metropolitan area population approaching 20 million. Meteorology also influenced differences among the cities. Concentrations of PM2.5 and components were generally higher in the winter than the summer, the latter being the rainy season. Black carbon, noted from heavy duty vehicles, composed up to $38 \%$ of the PM2.5 mass. Four of the cities had BC concentrations in the range of 3.5 to $4.5 \mu \mathrm{g} / \mathrm{m}^{3}$; São Paulo $10.6 \mu \mathrm{g} / \mathrm{m}^{3}$, all much higher than BC concentrations typically observed in most US cities. The number of deaths attributed to the excess PM2.5 concentrations above the WHO standard, by metropolitan region, was estimated based on an existing equation in the literature. These ranged from 0.3 to nearly 10 per thousand of population, the latter being in São Paulo.

Absolute principal component analysis (APCA) was used to apportion the data into factors that were then related to sources based on the chemical composition identified with each factor. The contribution of PM2.5 attributed to motor vehicle emissions could not be distinguished in all cities by the data obtained in this study due measured PM2.5 components distributing among several factors. For those that could be distinguished, motor vehicles made significant contributions ranging from $50 \%$ in Rio de Janeiro, 17\% Belo Horizonte. Motor vehicle emissions contributed about $40 \%$ in São Paulo. Soil and crustal material, biomass burning, and fuel oil combustion from various industries were other major sources identified as contributing to PM2.5 concentrations in these cities. The faction of PM2.5 mass not explained by APCA mostly ranged from about $20 \%$ to $30 \%$.

Higher concentrations of pollutants were typically observed in the garage relative to the kitchen and during vehicles' cold start mode independent of parameter 
Table 3 (continued)

\begin{tabular}{ll}
\hline $\begin{array}{l}\text { Authors/ } \\
\text { category }\end{array}$ & Study objective \\
\hline & $\begin{array}{l}\text { adjacent room (kitchen) due to the influence of vehicle } \\
\text { type (sedan versus pickup truck), its operational mode } \\
\text { (normal versus high emitting mode), and fuel type } \\
\text { (conventional versus oxygenated). }\end{array}$
\end{tabular}

Key finding

Traviss et al. To evaluate the impact of petroleum diesel and a soy2011 , this based blend $[20 \%$ biodiesel $/ 80 \%$ petroleum diesel issue (B20)] on occupational and environmental PM2.5, EC, and $\mathrm{OC}$ exposures at a municipal materials recovery facility utilizing heavy duty diesel nonroad equipment.

Valberg and Long 2011, this issue

To determine if county-by-county brain cancer incidence and mortality rates are correlated with geographical patterns of local ambient air pollution, including criteria pollutants (except $\mathrm{Pb}$ ) and a subset of EPA's identified HAPs.

Healy et al. To evaluate potential toxicological differences between 2011, this inorganic components observed in urban and rural PM issue as a function of season and toxicity as measured by an in vitro analysis that measured surrogates for oxidative stress, inflammatory response, and cytotoxicity. tested. In general higher concentrations of MSAT pollutants were observed in both locations from the truck than the sedan as well as higher concentrations observed during the high emitter mode. Higher concentrations of CO, 1,3-BD, BTEX and MTBE (for MTBE fuel) were observed in the garage and to a lesser degree in the kitchen for oxygenated fuels than for the petroleum fuel.

Concentrations/exposures of PM2.5 and EC in the various settings were significantly reduced when biodiesel fuel was employed compared to petroleum diesel use. PM2.5 and EC reductions ranged from $56 \%$ to $76 \%$ and from $5 \%$ to $29 \%$, respectively. However, concentrations of OC were increased during biodiesel use from $294 \%$ to $467 \%$. The authors suggest the higher OC maybe due to higher emissions of soluble organic carbon when soy diesel is used as noted previously in the literature or maybe due to variability in operating modes of the different sources in this real world study.

Slight positive correlations were observed with cattle density and brain cancer incidence and mortality rates and none were observed with the ambient pollutants included in this exploratory analysis.

Irrespective of season, the generation of ROS occurred at all three sites, although greater at the urban than rural site. Differences in the concentration of some transition metals between urban and rural areas may be the reason for the observed differences in ROS generation. Other parameters did not correlate with site. Results suggest that the toxicity parameter IL-6 is related to season since the highest IL- 6 responses were collected in the summer. as a subset of knowledge gaps based on the material presented to provide guidance for further research planning efforts.

The next two papers examine PM2.5 mass and composition in six major cities in Brazil, all of which are state capitals. The paper by Miranda et al. (2011, this issue) describes daily measurements of PM2.5 mass and composition that were obtained over more than a year in each of these cities at locations with high traffic volume but also influenced by other sources that varied depending on the city. Annual and seasonal average differences for PM2.5 mass and composition are described among the cities. Variations are described due to meteorology and known sources within each city. Excess deaths, estimated based on PM2.5 mass concentrations above the World Health Organization's (WHO) guidelines of $10 \mu \mathrm{g} / \mathrm{m}^{3}$ also are presented with a maximum observed value of 10 deaths per thousand people in São Paulo, a significant number since the city has a population of nearly 20 million people. Apportionment of sources at the same study sites using principal component analysis is described in the second paper by Andrade et al. (2011, this issue) focusing on the contribution of vehicle emissions to PM2.5. Vehicle emissions explained up to $50 \%$ of the PM2.5 mass. Other major sources that varied depending on the city included crustal material, biomass burning, and fuel oil combustion from industries. In Belo Horizonte, mining was the major source identified since it is located in an area of Brazil where there are large reserves of iron ore, gold, diamonds, phosphate, zinc, aluminum, limestone, and semiprecious stones.

Papers by Zielinska et al. (2011, this issue) and Traviss et al. (2011, this issue) examined differences in exposures to emissions from different fuel types. In the first paper, Zielinska et al. examined the effects on mobile source air toxics (MSAT) concentrations due to vehicle type (sedan versus pickup truck), operational mode (normal versus malfunction/high emitter), and fuel type (conventional versus oxygenated) and compared observed pollutant levels in the attached garage and adjacent kitchen to better understand exposure to individuals living in a similar 
house. Other possible emissions sources (gas can and lawn mower) typically observed in garage were included in all tests. Five scenarios were evaluated: (1) background, no vehicle; (2) hot soak vehicle; (3) cooling vehicle; (4) cold vehicle; and (5) cold start. Pollutants measured included $\mathrm{CO}, \mathrm{CO}_{2}$, BTEX (benzene, toluene, ethylbenzene, and xylenes), MTBE (methyl tertiary butyl ether), 1,3-butadiene (1,3-BD), formaldehyde, and acetaldehyde. Differences were observed between the garage and kitchen and between the truck and sedan as well as between fuel types depending on the scenario. The second paper (Traviss et al.), compares occupational and environmental exposures from petroleum diesel fuel and biodiesel (20\% soy-based blended with petroleum; B20) at an isolated municipal materials recovery facility that had four primary pieces of common nonroad equipment used to move materials around the facility. PM2.5, EC, and OC were measured at various locations in the facility including in the cabin of the equipment, work area, and near field. All equipment burned the same fuel over about a 2-week period and a change in fuel types in the equipment was separated by a transition period to ensure testing of the fuels independent of each other. PM2.5 and $\mathrm{EC}$ concentrations/exposures were found to be lower while $\mathrm{OC}$ values higher when the equipment in the facility burned B20, indicating a major change in PM composition.

Valberg and Long (2011, this issue) investigate associations between brain cancer rates and mortality and local ambient air pollution levels nationwide on a county-bycounty basis. They correlated geographical variations of incidence and mortality rates of brain cancer with geographical variations in exposure to criteria pollutants measured at EPA central site monitoring locations and inhalation exposure concentrations of 30 hazardous air pollutants (HAPs) as predicted by the U.S. EPA National Air Toxics Assessment. They also included the geographical density of domestic cattle, since viruses have been implicated in brain cancer and cattle are known for carrying a variety of viruses. A number of limitations were noted in this exploratory analysis, but overall, no correlations of significant magnitude were found suggesting that the ambient pollutants tested are not related to brain cancer

The final paper in this issue, by Healy et al. (2011, this issue) examines toxicological differences between the fine inorganic chemical components of PM, defined here as PM in the size range of 0.1 to $2.5 \mu \mathrm{m}$, and biological effects as determined by exposing in vitro human lung epithelial cells (A549) to the collected PM. Samples of fine PM were collected during different seasons at urban and rural locations in Cork, Ireland to allow for seasonal differences to be investigated. The toxicological experiments focused on oxidative stress, inflammatory response, and cytotoxicity by measuring the generation of intracellular ROS and the release of several proinflammatory mediators to represent cytokines involved with inflammation. Principal component analysis followed by partial least squares regression was used to examine associations between biological responses and composition. Some differences between rural and urban samples were noted including differences in PM composition and generation of ROS, both being higher in urban areas than rural. Seasonal differences were noted with some of the proinflammatory mediators.

Acknowledgments The 2010 AAAR Air Pollution and Health Conference would not have been possible if not for the generous support by a number of sponsors that included: U.S. EPA, Health Effects Institute, American Chemistry Council, American Petroleum Institute, California Air Resources Board - Research Division, Electric Power Research Institute, NARSTO, National Aeronautics and Space Administration, National Institute for Public Health and the Environment (RIVM), National Oceanic and Atmospheric Administration, South Coast Air Quality Management District, Southern Company, Air \& Waste Management Association, International Society of Exposure Sciences, and Springer. The American Association for Aerosol Research (AAAR), the professional society sponsoring the meeting, along with Association Headquarters, AAAR's management company, also was pivotal in making the conference a huge success. Special thanks are given to the conference co-chair, Maria Costantini, to conference committee members as listed at http:// aar.2010specialty.org/ and in the conference program (http:// aaar.2010specialty.org/pdfs/2010_Specialty_Conf_Final_Program. pdf), and to those who attended and participated in the meeting.

Declaration of interest The U.S. EPA through its Office of Research and Development funded and managed the development of this preface. It has been subjected to the agency's administrative review and approved for publication.

\section{References}

Andrade MF, Miranda RM, Fornaro A, Kerr A, Oyama B, Andre PA, Saldiva P (2011) Vehicle emissions and PM2.5 mass concentrations in six Brazilian cities. Air Qual Atmos Health. doi:10.1007/s11869-010-0104-5

Davisdon CI, Phalen RF, Solomon PA (2005) Airborne particulate matter and human health: a review. Aerosol Sci Technol 39:737-749

EPA (2006a) Air quality criteria for ozone and related photochemical oxidants (2006 Final). U.S. Environmental Protection Agency, Washington, DC, EPA/600/R-05/004aF-cF

EPA (2006b) Air quality criteria for lead (2006) final report. U.S. Environmental Protection Agency, Washington, DC, EPA/600/R05/144aF-bF

EPA (2008a) Integrated science assessment for oxides of nitrogenhealth criteria (final report). EPA/600/R-08/071

EPA (2008b) Integrated science assessment (ISA) for sulfur oxides health criteria (final report). U.S. Environmental Protection Agency, Washington, DC, EPA/600/R-08/047F

EPA (2009) Integrated science assessment for particulate matter (final report). U.S. Environmental Protection Agency, Washington, DC, EPA/600/R-08/139F

EPA (2010) Integrated science assessment for carbon monoxide (final report). U.S. Environmental Protection Agency, Washington, DC, EPA/600/R-09/019F 
Healy DA, Hellebust S, Silvari V, Lopez JM, Whittaker AG, Wenger GC, Heffron JJA, Sodeau JR (2011) Using a pattern recognition approach to link inorganic chemical fingerprints of ambient PM2.5-0.1 with in vitro biological effects. Air Qual Atmos Health. doi:10.1007/s11869-010-0120-5

Miranda RM, Andrade MF, Fornaro A, Astolfo R, André PA, Saldiva P (2011) Urban air pollution: a representative survey of PM2.5 mass concentrations in six Brazilian cities. Air Qual Atmos Health. doi:10.1007/s11869-010-0124-1

NRC (1998) Research priorities for airborne particulate matter, I. Immediate priorities and a long-range research portfolio; National Research Council; National Academies Press: Washington

NRC (1999) Research priorities for airborne particulate matter, II. Evaluating research progress and updating the portfolio; National Research Council; National Academies Press: Washington

NRC (2001) Research priorities for airborne particulate matter, III. Early research progress; National Research Council; National Academies Press: Washington

NRC (2004) Research priorities for airborne particulate matter, IV. Continuing research progress; National Research Council; National Academies Press: Washington

Solomon PA (2010) Preface: special issue of Inhalation Toxicology for air pollution and health: bridging the gap from sources-to-health outcomes. Solomon PA; Guest ed. Inhalation Toxicology 22(S2), $1-5: 2010$

Solomon PA (2011a) Introduction: special issue of Air Quality, Atmosphere and Health for air pollution and health: addressing science questions to inform science and policy. Solomon PA, Guest ed. Air Qual Atmos Health (in preparation)
Solomon PA (2011b) Editorial: special issue of Environmental Health Perspectives for air pollution and health: bridging the gap from sources-to-health outcomes. Solomon PA, Guest ed. Environ Health Perspect 119(4):156A-157A. doi:10.1289/ehp.1103660

Solomon PA (2011c) Preface: special issue of Aerosol Science and Technology for air pollution and health: bridging the gap from sources-to-health outcomes. Solomon PA, Guest ed. Aerosol Sci Technol 45:i-vii

Solomon PA, Costantini M, Grahame TJ, Gerlofs-Nijland ME, Cassee F, Russell AG, Brook JR, Hopke PK, Hidy G, Phalen RF, Saldiva P, Ebelt Sarnat S, Balmes JR, Tager IB, Özkaynak H, Vedal S, Wierman SSG, Costa DL (2011a) Air Pollution and Health: Bridging the Gap from Sources to Health Outcomes: conference summary. Air Qual Atmos Health. doi:10.1007/s11869-0110161-4

Solomon PA, Wexler A, Sioutas C (2011b) Preface: special issue of Atmospheric Environment for air pollution and health: bridging the gap from sources-to-health outcomes. Solomon PA, Wexler A, Sioutas C, Guest eds. Atmos Environ (in preparation)

Traviss N, Thelen BA, Ingalls JK, Treadwell MD (2011) Evaluation of biodiesel's impact on real world occupational and environmental particulate matter exposures at a municipal facility in Keene, $\mathrm{NH}$. Air Qual Atmos Health. doi:10.1007/s11869-011-0141-8

Valberg PA, Long CM (2011) Do brain cancer rates correlate with ambient exposure levels of criteria air pollutants or hazardous air pollutants (HAPs)? doi:10.1007/s11869-010-0122-3

Zielinska B, Fujita E, Ollison W, Campbell D, Sagebiel J, Merritt P, Smith L (2011) Relationships of attached garage and home exposures to fuel type and emission levels of garage sources. Air Qual Atmos Health. doi:10.1007/s11869-010-0121-4 